\title{
Cox-maze IV cryoablation and postoperative heart failure in mitral valve surgery patients
}

\author{
Gabriella Boano, Meriam Åström Aneq, Jennie Kemppi and Farkas Vánky \\ Journal Article
}

Tweet

N.B.: When citing this work, cite the original article.

This is an electronic version of an article published in:

Gabriella Boano, Meriam Åström Aneq, Jennie Kemppi and Farkas Vánky, Cox-maze IV cryoablation and postoperative heart failure in mitral valve surgery patients., Scandinavian Cardiovascular Journal, 2017. 51(1),

Scandinavian Cardiovascular Journal is available online at informaworldTM:

http://dx.doi.org/10.1080/14017431.2016.1196827

Copyright: Taylor \& Francis: STM, Behavioural Science and Public Health Titles http://www.tandf.co.uk/journals/default.asp

Postprint available at: Linköping University Electronic Press

http://urn.kb.se/resolve?urn=urn:nbn:se:liu:diva-134010

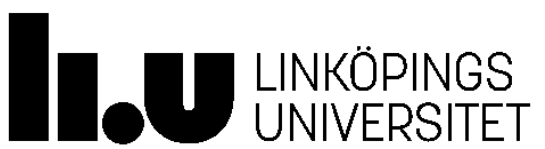




\section{Cox-maze IV cryoablation and postoperative heart failure in}

\section{mitral valve surgery patients}

Running head: AF ablation and postoperative heart failure

Gabriella Boano, MD, ${ }^{1,2}$ Meriam Åström Aneq, MD, PhD, ${ }^{1,3}$ Jennie Kemppi, DMS, ${ }^{1,3}$ Farkas Vánky, MD, $\mathrm{PhD}^{1,2}$

${ }^{1}$ Division of Cardiovascular Medicine, Department of Medical and Health Sciences, Faculty of Health Sciences, Linköping University, Linköping, Sweden, ${ }^{2}$ Department of Cardiothoracic Surgery, Heart \& Medicine Centre, Linköping, Sweden, ${ }^{3}$ Department of Clinical Physiology, Heart \& Medicine Centre, Linköping, Sweden

This work has partly been presented at the 7th Joint Conference in Cardiothoracic Surgery in Bergen, Norway (September 3-5, 2015)

Address reprint request to: Dr. Farkas Vánky, Dept. of Cardiothoracic and Vascular Surgery, Linköping Heart Centre, University Hospital, SE-581 85 Linköping, Sweden. Phone: +46 101030128. Fax: +46 13 100246. E-mail: farkas.vanky@regionostergotland.se 


\section{Abstract}

Objective: The indications for risks and benefits of concomitant surgical ablation for atrial fibrillation (AF) have not been fully delineated. Our aim was to survey whether the Cox-maze IV procedure is associated with postoperative heart failure (PHF) or other adverse short-term outcomes after mitral valve surgery (MVS).

Design: Consecutive patients with AF undergoing MVS with $(n=50)$ or without $(n=66)$ concomitant Cox-maze IV cryoablation were analysed regarding perioperative data and one year mortality.

Results: The patients in the Maze group were younger, were in lower NYHA classes, had better right ventricular function, and had lower pulmonary artery pressure. The Maze group had 30 minutes longer median cross-clamp time (CCT) and 50\% had PHF compared with $33 \%$ in the No-maze group, $\mathrm{p}=0.09$. Two patients in the No-maze group died within one year of surgery. Congestive heart failure (OR 4.3 [CI 95\%: 1.8-10], $\mathrm{p}<0.0001$ ) and CCT (OR 1.03 [CI 95\%: 1.01-1.04], $\mathrm{p}=0.001$ ) were associated with PHF.

Conclusion: The current data cannot exclude that concomitant cryoablation increases the risk for postoperative heart failure, possibly by increasing the cross clamp time. 


\section{Introduction}

Atrial fibrillation (AF) is the most common cardiac arrhythmia, with an incidence of $0.5-1 \%$ in the general population, and the prevalence increases with age (1). AF is associated with increased morbidity and mortality (1). There are several treatments for AF but the Cox-maze III cut and sew surgical procedure is the one with the best results in terms of restored sinus rhythm at long-term follow-up $(2,3)$. This procedure is still the reference standard for surgical treatment of AF but it is mostly used in stand-alone surgery for AF due to its technical complexity (4). Ablative lesions created with different energy sources (Cox-maze IV) have mainly replaced the cut and sew lines in AF treatment concomitant to other cardiac surgery $(5,6)$.

The 2012 Heart Rhythm Society/European Heart Rhythm Society/European Cardiac Arrhythmia Society guidelines recommend AF intervention as an acceptable treatment in symptomatic patients, concomitant to other cardiac surgery (7). Theories and studies that suggest a decreased risk for stroke, an improved quality of life, a decreased risk for heart failure, and an improved survival with achievement of sinus rhythm after cardiac surgery have led to a more liberal implementation of concomitant AF procedure, particularly in mitral valve surgery (MVS) $(7,8)$.

AF treatment added to other cardiac surgery does not seem to increase short-term mortality, reoperation for bleeding, stroke, low cardiac output syndrome, deep sternal wound infection, prolonged ventilation, or renal failure (8-10). However, it increases the cross-clamp time (CCT) and the intensive care unit stay, and it may increase the need for a permanent pacemaker postoperatively $(8,11-13)$.

Postoperative heart failure (PHF) is one of the major determinants for adverse outcome in cardiac surgery (14-16). Most of the in-hospital mortality after coronary bypass surgery is 
related to PHF, and patients with PHF after surgery for aortic stenosis have a $42 \%$ mortality rate at five-year follow-up (16). Our hypothesis was that the Cox-maze IV cryoablation procedure added to MVS is associated with PHF and other adverse short-term outcomes.

\section{Material and methods}

Consecutive patients with preoperative nonparoxysmal AF undergoing MVS between Nov 2009 and June 2013 were identified in our institutional database. Sixty-six patients had no concomitant ablation procedure (No-maze group) and 50 patients had concomitant Cox-maze IV biatrial cryoablation (Maze group), using the argon powered Cardioblate ${ }^{\circledR}$ CryoFlex ${ }^{\mathrm{TM}}$ Surgical Ablation Probe (Medtronic Inc., Minneapolis, MN, USA). The decision to add the Cox-maze IV procedure to MVS was made by the surgeon. The cryoablation probe was applied for 120 seconds at full power and usually it reached $-150^{\circ} \mathrm{C}$ but always at least $130^{\circ} \mathrm{C}$. The removal of the probe was aided by irrigation with warm saline. The left atrial lesion set consisted of a circular line isolating the four pulmonary vein orifices, a coronary sinus lesion from the atrial incision through the mitral annulus, and a left atrial appendage line connected to the circular pulmonary vein lesion. The right atrial lesions included an intercaval line between the superior and the inferior vena cava crossing the right atrial incision, a " $\mathrm{T}$ " lesion from the right atrial incision to the posterior portion of the tricuspid annulus, and a lesion from the right atrial appendage to the anterior portion of the tricuspid annulus (17). Mitral valve repair was performed in 34(68\%) of the patients in the Maze group and in $46(70 \%)$ of the patients in the No-maze group. The left atrial appendage was suture-closed from the inside of the left atrium in 10(20\%) of the Maze patients and in 4(6\%) of the Nomaze patients, $\mathrm{p}=0.04$. 
The procedures were performed by nine consultant surgeons and three of them performed 99 of the 116 operations. The perioperative care was supervised by 14 consultant anaesthesiologists. Clinical data and mortality were collected retrospectively from the institutional database, clinical records, and from the Swedish Civil Registry. One-year rhythm outcome was based on multiple electrocardiograms, on 24 - 48 hours Holter monitoring (33\%), and on registrations from permanent pacemakers (29\%) in the period from 10 to 14 months postoperatively. Study approval was obtained from the Regional Ethical Review Board in Linköping, Sweden (Dnr. 2012/371-31).

PHF was defined as a haemodynamic state when the cardiac output does not meet the systemic demand without supportive measures other than correction of volume or vascular resistance. Such supportive measures or treatment consisted of an intra-aortic balloon pump or ventricular assist device, or infusion of one or more inotropes for more than 30 minutes in dosages as listed below: Epinephrine $\geq 0.033 \mathrm{mg} / \mathrm{kg}$ of body weight per minute, milrinone $\geq 0.375 \mathrm{mg} / \mathrm{kg}$ of body weight per minute, dopamine $\geq 4 \mathrm{mg} / \mathrm{kg}$ of body weight per minute, dobutamine $\geq 4 \mathrm{mg} / \mathrm{kg}$ of body weight per minute, or levosimendan regardless of dose.

\section{Clinical management}

Standard monitoring was used consisting of a five-lead electrocardiogram, pulse oximetry, continuous arterial blood pressure monitoring, central venous pressure, and transoesophageal echocardiography. A median sternotomy was performed and combined anterograde and retrograde blood cardioplegia was employed in all patients. A surgical pulmonary artery catheter was introduced in all patients before weaning from extracorporeal circulation (18).

\section{Echocardiography}


Boano et al.

Images were recorded from standard views, according to the recommendations of the American Society of Echocardiography for transthoracic studies (19). The long-axis parasternal view was used to derive the M-mode measurement of the left ventricular diameter. The right ventricular inflow diameter and the left and right atrial areas were calculated from the four chamber view. Tricuspid annular plane systolic excursion was recorded at the right ventricular free wall using the cross sectional guided M-mode. The systolic pulmonary arterial pressure was calculated using the tricuspid regurgitation velocity to obtain a systolic transvalvular pressure gradient. Estimated right atrial pressure based on vena cava size and collapse was then added to the obtained gradient. The systolic left ventricular function was assessed using eyeballing combining the regional ventricular function abnormalities and the haemodynamic adaptation to eventual volume overload. The result was graded in normal, mild, moderate or severe left ventricular dysfunction.

\section{Statistical analysis}

Categorical variables are presented as numbers (percent) and continuous variables as medians $\left(1^{\text {st }}-3^{\text {rd }}\right.$ quartile). Nonparametric tests (Mann-Whitney U test and Fisher's exact test) were used for comparison between groups. Kaplan-Meier analysis was conducted to illustrate the cumulative survival for the groups. Univariate logistic regression was used for the evaluation of the association between different variables and PHF. Collinearity diagnostics were performed and no signs of multicollinearity were found. The confounding effects of congestive heart failure, CCT, and cryo-maze ablation were tested in a multivariate model. None of the two other variables changed the odds ratio of CCT for PHF $>10 \%$. Statistical analyses were performed with computerized statistical packages (Statistica 10.0, StatSoft Inc, Tulsa, OK, USA) and IBM SPSS Statistics 22.0 (IBM Corp., Armonk, NY, USA.). 


\section{Results}

The surgical procedures are listed in Table 1 . Fewer coronary artery bypass procedures were performed in the Maze group compared to the No-maze group, five(10\%) v 21(32\%), $\mathrm{p}=0.006$.

Preoperative and intraoperative data

The baseline characteristics for both groups are given in Table 2. The patients in the Maze group were younger, less frequently had a history of angina pectoris, were in lower NYHA classes, had higher blood haemoglobin, and they also had higher creatinine clearance. On the echocardiogram, tricuspid annular plane systolic excursion was higher and the pulmonary artery pressure was lower in the Maze group. However, there was no significant difference in EuroSCORE II between the groups. CCT was 127(111-140) and 97(79-118) minutes ( $p<0.0001)$, extracorporeal circulation time was 178(154-209) and 140(109-169) minutes $(\mathrm{p}<0.0001)$, and surgery time was $257(223-315)$ and $220(190-280)$ minutes $(p=0.001)$ in the Maze group and in the No-maze group, respectively.

\section{Postoperative outcomes}

Markers for myocardial injury were significantly higher in the Maze group on the first postoperative day. Postoperative in-hospital results are shown in Table 3. At discharge from our hospital, 32(64\%) of the patients in the Maze group were free from AF and at the oneyear follow-up, 40(83\%) had no evidence of AF. The need for permanent pacemaker 
implantation was $11(22 \%)$ v $14(21 \%), \mathrm{p}=0.82$, at one month and $13(26 \%) \mathrm{v} 16(24 \%), \mathrm{p}=1.0$ at the one-year follow-up in the Maze group and in the No-maze group, respectively. The Kaplan-Meier cumulative proportional survival curves are shown in Figure 1.

\section{Postoperative heart failure}

PHF presented in all patients at weaning from extracorporeal circulation except for two patients in each group in whom PHF was evident within 24 hours after surgery. Eight patients (16\%) in the Maze group and 20 patients (30\%) in the No-maze group $(p=0.8)$ were weaned from extracorporeal circulation without any inotrope support. Two patients needed an intraaortic balloon pump in the Maze group at weaning from cardiopulmonary bypass. They had CCT of 144 and 240 minutes and the intra-aortic balloon pump treatments lasted for one and four days, respectively. One patient in each group was treated with an extracorporeal membrane oxygenator. The patient in the Maze group had CCT for 172 minutes and the extracorporeal membrane oxygenation treatment started at weaning from extracorporeal circulation and lasted for nine days. The patient in the No-maze group had CCT for 105 minutes and a postoperative coagulopathy leading to four reoperations for bleeding within 24 hours from the index surgery. The extracorporeal membrane oxygenation treatment started after the fourth reoperation and lasted for six days.

Patients with PHF (n=47) needed longer ventilator treatment (7 [7-18] v 4 [3-5] hours, $\mathrm{p}<0.0001)$, a longer time in the intensive care unit (28 [21-91] v 21 [20-22] hours, $\mathrm{p}=0.0002)$, and more of the PHF patients had $>50 \%$ postoperative creatinine elevation (15\% v 4\%, $\mathrm{p}=0.04)$ compared with the patients without PHF $(\mathrm{n}=69)$. One patient with PHF and one without PHF died within the one-year follow-up period. 


\section{Variables associated with PHF}

Univariate associations between PHF and variables of interest are given in Table 4. No confounding effects were found between congestive heart failure, CCT, and cryo-maze ablation in relation to PHF. In the multivariate model CCT had OR 1.02 [CI 95\%: 1.01-1.04] ( $p=0.008)$ and congestive heart failure had OR 3.5 [CI 95\%: 1.5-8.4], $p=0.005$ in association with PHF. Cryo-maze ablation did not reach statistical significance when it was included in the model (OR 1.1 [CI 95\%: 0.5-2.9], p=0.8) and it did not significantly influence the impact of CCT and congestive heart failure. An exclusion of CCT from the model did not make cryomaze ablation become significantly associated with PHF (OR 1.9 [CI 95\%: 0.9-4.3], p=0.11).

\section{Discussion}

Surgeons' concern about increased morbidity associated with the Cox-maze IV procedure may partly explain why most of the cardiac surgery patients with AF are left untreated in spite of the present recommendations $(8,20,21)$. The selection of patients for concomitant surgical AF treatment is based on symptoms but is also influenced by expected success contra complication rates. In the case of structural cardiac pathology, arrhythmia-related symptoms such as fatigue and effort intolerance are often difficult to distinguish from symptoms related to valve dysfunction. As seen in our study, MVS in patients with AF includes, to a large extent, patients in need of other cardiac surgery procedures, which increases the surgical complexity and suggests a higher risk of adverse outcomes. Better definition of parameters correlated to adverse outcome would enhance patient selection.

The connection we found between PHF and early postoperative morbidity is in accordance with previous studies on other patient categories $(14,16,22)$. The incidence of PHF was $41 \%$ in patients with AF undergoing MVS in our study, which is higher than the reported 5-15\% of 
PHF for other cardiac surgery patient groups (23-26). In this study, PHF presented at weaning from extracorporeal circulation and was associated with prolonged respiratory treatment and increased renal impairment. The $2.0 \%$ one-year mortality in patients with PHF was lower than the predicted early postoperative mortality indicated by EuroSCORE II (5.8\%) and it was considerably lower than in patients with PHF after coronary surgery (25.5\%) (16). In patients with PHF after surgery for aortic stenosis, an 8.9\% one-year mortality was reported but the mortality rose to $42.2 \%$ at the five-year follow-up (16). Obviously the impact of PHF on postoperative mortality is different for different patient groups. Whether PHF has a larger impact on the long-term mortality than it has on the one-year mortality in patients with AF undergoing MVS remains to be shown.

Patients in the Maze group were younger, had a lower rate of coronary artery disease, were in lower NYHA classes, had a higher blood haemoglobin level, higher creatinine clearance, better longitudinal right ventricle function, and lower pulmonary artery pressure. However, we found no significant differences in postoperative outcome with regard to mortality, stroke, reoperation for bleeding, postoperative renal failure or length of intensive care unit stay between the two groups.

In spite of the more favourable preoperative state of the Maze group, the incidence of PHF was close to significantly higher compared with the No-maze group ( $50 \% \mathrm{v} 33 \%, \mathrm{p}=0.09)$. The strong association of CCT and congestive heart failure with PHF was, however, not confounded by the Cox-maze IV procedure. We cannot preclude that the Cryo-maze procedure increases the risk of PHF in patients with congestive heart failure undergoing complex cardiac surgery, not least by adding approximately 30 minutes to the CCT. Preoperative left ventricular dysfunction seems to play a less important role for PHF after MVS in patients with AF than in patients operated upon for aortic stenosis (22). Perioperative myocardial infarction is related to PHF after both coronary and aortic stenosis surgery (22, 
23). The cryoablation procedure itself results in elevation of markers for myocardial injury by atrial myocyte destruction (27). This prevents evaluation of the perioperative ventricular injury and thereby the diagnosis of perioperative myocardial infarction.

The Cox-maze IV cryoablation procedure seems not to affect the need for a permanent pacemaker when conducted concomitant to MVS in spite of the $83 \%$ freedom from AF in the Maze group at the one-year follow-up. The reported freedom of AF one year after MVS without concomitant AF procedure is varying from approximately 30-43\% $(12,28)$.

This study has certain limitations that should be acknowledged. It was not prospective and the patient selection for concomitant maze surgery was based on the surgeon’s decision which means the groups were not fully comparable. Conclusions on outcome comparisons between the groups must be made with caution. The limited size of the groups and the low incidence of early postoperative mortality impede an analysis of factors related to one-year mortality. There is no generally accepted criterion for PHF and our definition is dependent on the individual judgement of various surgeons and anaesthesiologists which may partly explain the high incidence of PHF in our patients with AF undergoing MVS. However, this definition of PHF applied on aortic valve surgery and coronary artery surgery resulted in $11 \%$ and $12 \%$ of PHF, respectively, which is comparable whith the $5-15 \%$ of PHF in other studies on aortic valve and coronary artery surgery (23). At our institution a reliance on mixed venous oxygen saturation and echocardiographic appearance rather than fixed haemodynamic criteria are used to diagnose PHF $(22,23)$.

\section{Summary}

We cannot exclude that the addition of the Cox-maze IV cryoablation procedure to MVS increases the risk for postoperative heart failure. It can, however, be conducted with a low 
one-year mortality at least in a selected group of younger patients in a lower New York Heart Association class, and with a better renal function. A concomitant cryo-maze procedure should be applied with caution in patients needing complex surgical procedures with long expected CCT. PHF after MVS in patients with preoperative AF is frequent and results in prolonged ventilator treatment and increased time in the intensive care unit.

\section{Acknowledgements and disclosure}

The authors thank Karl Wahlin and Mats Fredrikson for their contribution to the statistical analyses. Financial support was received from the ALF funding, County Council of Östergötland, Sweden. The authors report no relationship with industry and no conflicts of interest.

\section{References}

1. Chugh SS, Blackshear JL, Shen WK, Hammill SC, Gersh BJ. Epidemiology and natural history of atrial fibrillation: Clinical implications. J Am Coll Cardiol 2001;37:371-378.

2. Cox JL, Boineau JP, Schuessler RB, Jaquiss RD, Lappas DG. Modification of the maze procedure for atrial flutter and atrial fibrillation. I. Rationale and surgical results. J Thorac Cardiovasc Surg 1995;110:473-484.

3. Stulak JM, Suri RM, Burkhart HM, Daly RC, Dearani JA, Greason KL et al. Surgical ablation for atrial fibrillation for two decades: Are the results of new techniques equivalent to the cox maze iii procedure? J Thorac Cardiovasc Surg 2014;147:1478-1486.

4. Prasad SM, Maniar HS, Camillo CJ, Schuessler RB, Boineau JP, Sundt $3^{\text {rd }}$ TM et al. The cox maze iii procedure for atrial fibrillation: Long-term efficacy in patients undergoing lone versus concomitant procedures. J Thorac Cardiovasc Surg 2003;126:1822-1828. 
5. Khargi K, Hutten BA, Lemke B, Deneke T. Surgical treatment of atrial fibrillation; a systematic review. Eur J Cardiothorac Surg 2005;27:258-265.

6. Melby SJ, Lee AN, Damiano RJ. Advances in surgical ablation devices for atrial fibrillation. In: Wang P, ed. New arrhythmia technologies. Malden, MA: Blackwell Publishing; 2005:233-241.

7. Calkins H, Kuck KH, Cappato R, Brugada J, Camm JA, Chen S et al. 2012 HRS/EHRA/ECAS expert consensus statement on catheter and surgical ablation of atrial fibrillation: Recommendations for patient selection, procedural techniques, patient management and follow-up, definitions, endpoints, and research trial design: A report of the heart rhythm society (HRS) task force on catheter and surgical ablation of atrial fibrillation. Heart Rhythm 2012;9:632-696.

8. Gammie JS, Haddad M, Milford-Beland S, Welke KF, Ferguson TB Jr, O’Brien SM et al. Atrial fibrillation correction surgery: Lessons from the Society of Thoracic Surgeons national cardiac database. Ann Thorac Surg 2008;85:909-914.

9. Yoo JS, Kim JB, Ro SK, Jung Y, Jung SH, Choo SJ et al. Impact of concomitant surgical atrial fibrillation ablation in patients undergoing aortic valve replacement. Jpn Circ J 2014;78:1364-1371.

10. Ad N, Holmes SD, Pritchard G, Shuman DJ. Association of operative risk with the outcome of concomitant cox maze procedure: A comparison of results across risk groups. J Thorac Cardiovasc Surg 2014;148:3027-3033.

11. Budera P, Straka Z, Osmancik P, Vanek T, Jelinek S, Hlavicka J et al. Comparison of cardiac surgery with left atrial surgical ablation vs. Cardiac surgery without atrial ablation in patients with coronary and/or valvular heart disease plus atrial fibrillation: Final results of the PRAGUE-12 randomized multicentre study. Eur Heart J 2012;33:2644-2652. 
12. Blomstrom-Lundqvist C, Johansson B, Berglin E, Nilsson L, Jensen SM, Thelin S et al. A randomized double-blind study of epicardial left atrial cryoablation for permanent atrial fibrillation in patients undergoing mitral valve surgery: The SWEdish Multicentre Atrial Fibrillation study (SWEDMAF). Eur Heart J 2007;28:2902-2908.

13. Ad N, Holmes SD, Massimiano PS, Pritchard G, Stone LE, Henry L. The effect of the cox-maze procedure for atrial fibrillation concomitant to mitral and tricuspid valve surgery. J Thorac Cardiovasc Surg 2013;146:1426-1434.

14. O'Connor GT, Birkmeyer JD, Dacey LJ, Quinton LJ, Marrin HB, Birkmeyer CA et al. Results of a regional study of modes of death associated with coronary artery bypass grafting. Northern New England cardiovascular disease study group. Ann Thorac Surg 1998;66:1323-1328.

15. Surgenor SD, O'Connor GT, Lahey SJ, Quinn R, Charlesworth DC, Dacey LJ et al. Predicting the risk of death from heart failure after coronary artery bypass graft surgery. Anesth Analg 2001;92:596-601.

16. Vanky FB, Hakanson E, Svedjeholm R. Long-term consequences of postoperative heart failure after surgery for aortic stenosis compared with coronary surgery. Ann Thorac Surg 2007;83:2036-2043.

17. Cox JL. A brief overview of surgery for atrial fibrillation. Ann Cardiothorac Surg 2014;3:80-88.

18. Holm J, Hakanson E, Vanky F, Svedjeholm R. Mixed venous oxygen saturation predicts short- and long-term outcome after coronary artery bypass grafting surgery: A retrospective cohort analysis. Br J Anaesth 2011;107:344-350.

19. Picard MH, Adams D, Bierig SM, Dent JM, Douglas PS, Gillam LD et al. American society of echocardiography recommendations for quality echocardiography laboratory operations. J Am Soc Echocardiogr 2011;24:1-10. 
20. Ad N, Cheng DC, Martin J, Berglin E, Chang BC, Doukas G et al. Surgical ablation for atrial fibrillation in cardiac surgery: A consensus statement of the international society of minimally invasive cardiothoracic surgery (ISMICS) 2009. Innovations 2010;5:74-83.

21. Ad N, Henry L, Hunt S, Holmes SD. Should surgical ablation for atrial fibrillation be performed in patients with a significantly enlarged left atrium? J Thorac Cardiovasc Surg 2014;147:236-241.

22. Vanky FB, Hakanson E, Tamas E, Svedjeholm R. Risk factors for postoperative heart failure in patients operated on for aortic stenosis. Ann Thorac Surg 2006;81:1297-1304.

23. Vanky F, Hakanson E, Maros T, Svedjeholm R. Different characteristics of postoperative heart failure after surgery for aortic stenosis and coronary disease. Scand Cardiovasc J 2004;38:152-158.

24. Jarvinen A. Low-output syndrome as a complication of open-heart surgery in 85 patients. Ann Clin Res 1975;7:379-393.

25. Shernan SK, Fitch JC, Nussmeier NA, Chen JC, Rollins SA, Mojcik CF et al. Impact of pexelizumab, an anti-C5 complement antibody, on total mortality and adverse cardiovascular outcomes in cardiac surgical patients undergoing cardiopulmonary bypass. Ann Thorac Surg 2004;77:942-950.

26. Hogue CW, Jr., Sundt T, 3rd, Barzilai B, Schecthman KB, Davila-Roman VG. Cardiac and neurologic complications identify risks for mortality for both men and women undergoing coronary artery bypass graft surgery. Anesthesiology 2001;95:1074-1078.

27. Martinez-Comendador J, Castano M, Mosquera I, Plana JG, Gualis J, Martin CE et al. Cryoablation of atrial fibrillation in cardiac surgery: Outcomes and myocardial injury biomarkers. J Cardiothorac Vasc Anesth 2011;25:1030-1035. 
28. Gillinov AM, Gelijns AC, Parides MK, DeRose JJ, Moskowitz AJ, Voisine P et al. Surgical ablation of atrial fibrillation during mitral-valve surgery. N Engl Med 2015;372:1399-409. 


\section{Tables}

Table 1. The different surgical procedures performed.

\begin{tabular}{lcc}
\hline & Maze $\mathrm{n}=50$ & No-maze $\mathrm{n}=66$ \\
\hline MVS & 7 & 11 \\
MVS + TVS & 35 & 30 \\
MVS + CABG & 1 & 2 \\
MVS + AVR & 1 & 1 \\
MVS + aortic surgery & 0 & 10 \\
MVS + TVS + CABG & 3 & 1 \\
MVS + TVS + AVR & 2 & 1 \\
MVS + TVS + AVR + CABG & 1 & 1 \\
MVS + TVS + CABG + AVR + aortic surgery & 0 & \\
\hline
\end{tabular}

AVR = aortic valve surgery; CABG = coronary artery bypass grafting; $\mathrm{MVS}=$ mitral valve surgery; TVS = tricuspid valve surgery. 
Table 2. Baseline patient characteristics.

\begin{tabular}{|c|c|c|c|}
\hline & Maze $n=50$ & No-maze $n=66$ & $p$ Value \\
\hline Age (years) & $68(64-74)$ & $75(67-78)$ & 0.001 \\
\hline Female gender & $16(32 \%)$ & $23(35 \%)$ & 0.84 \\
\hline Body mass index $\left(\mathrm{kg} / \mathrm{m}^{2}\right)$ & $25(23-27)$ & $26(23-28)$ & 0.42 \\
\hline Insulin or orally treated diabetes mellitus & 0 & $2(3 \%)$ & 0.23 \\
\hline Chronic obstructive pulmonary disease & $2(4 \%)$ & $4(6 \%)$ & 0.70 \\
\hline Cerebrovascular disease & $5(10 \%)$ & $6(9.2 \%)$ & 1.0 \\
\hline Peripheral artery disease & $3(6 \%)$ & $4(6.1 \%)$ & 1.0 \\
\hline Hypertension & $14(57 \%)$ & $29(44 \%)$ & 0.12 \\
\hline Angina pectoris & $2(4 \%)$ & $18(27 \%)$ & 0.001 \\
\hline History of congestive heart failure & $32(64 \%)$ & 37 (56\%) & 0.45 \\
\hline New York Heart Association class III/IV & $26(52 \%)$ & $57(86 \%)$ & 0.0001 \\
\hline EuroSCORE II & $3.7(2.3-6.3)$ & $4.1(2.6-6.3)$ & 0.50 \\
\hline Blood Haemoglobin (g/L) & $143(133-152)$ & $134(124-144)$ & 0.002 \\
\hline Creatinine clearance (ml/min) & $75(61-89)$ & $63(46-86)$ & 0.03 \\
\hline Creatinine clearance $<50 \mathrm{ml} / \mathrm{min}$ & $9(18 \%)$ & $21(32 \%)$ & 0.13 \\
\hline Previous cardiac surgery & $1(2 \%)$ & $5(8 \%)$ & 0.23 \\
\hline Previous myocardial infarction within 90 days & $1(2 \%)$ & $5(8 \%)$ & 0.24 \\
\hline \multicolumn{4}{|l|}{ Echocardiography data } \\
\hline LV dysfunction moderate or severe & $4(8 \%)$ & $10(16 \%)$ & 0.26 \\
\hline LV diameter index ( $\left.\mathrm{LV} / \mathrm{BSA}\left(\mathrm{mm} / \mathrm{m}^{2}\right)\right)$ & $29(26-31)$ & $30(27-33)$ & 0.13 \\
\hline $\mathrm{RV}$ diameter index $\left(\mathrm{RV} / \mathrm{BSA}\left(\mathrm{mm} / \mathrm{m}^{2}\right)\right)$ & $21(19-23)$ & $21(19-23)$ & 0.97 \\
\hline $\mathrm{LA}$ area index $\left(\mathrm{LA} / \mathrm{BSA}\left(\mathrm{mm}^{2} / \mathrm{m}^{2}\right)\right)$ & $17(14-20)$ & $17(14-20)$ & 0.57 \\
\hline
\end{tabular}


Boano et al.

\begin{tabular}{lccr}
\hline RA area index (RA/BSA $\left.\left(\mathrm{mm}^{2} / \mathrm{m}^{2}\right)\right)$ & $12(10-14)$ & $13(11-15)$ & 0.13 \\
Tricuspid annular plane systolic excursion $(\mathrm{mm})$ & $19(17-22)$ & $17(15-20)$ & 0.008 \\
Pulmonary artery pressure (mmHg) & $40(35-45)$ & $45(40-55)$ & 0.001 \\
\hline
\end{tabular}

Results are given as $\mathrm{n}(\%)$ or as median $\left(1^{\text {st }}-3^{\text {rd }}\right.$ quartile $)$. BSA = body surface area; LA = left atrium; LV = left ventricle; $\mathrm{RA}=$ right atrium; $\mathrm{RV}=$ right ventricle. 
Table 3. Postoperative in-hospital outcomes.

Maze $\mathrm{n}=50 \quad$ No-maze $\mathrm{n}=66 \quad p$ Value

Plasma ASAT, day $1(\mu \mathrm{kat} / \mathrm{L})$

Plasma CK-MB, day 1 ( $\mu \mathrm{g} / \mathrm{L})$

Plasma Creatinine elevation $>50 \%$

Plasma Creatinine at discharge $(\mu \mathrm{mol} / \mathrm{L})$

Dialysis

Time on ventilator (h)

Time on ventilator $>24$ hrs

ICU-stay (h)

ICU-stay $>72$ hrs

Reoperation for tamponade/bleeding

Reoperation for sternal infection

Stroke

Postoperative heart failure
$3.7(3.0-4.5)$

$118(94-147)$

$4(8 \%)$

77 (60-92)

$1(2 \%)$

$5(3-9)$

$7(14 \%)$

57 (44-103)

$8(16 \%)$

$3(6 \%)$

$1(2 \%)$

0

$25(50 \%)$
$1.4(1.1-2.0) \quad<0.0001$

$33(26-50) \quad<0.0001$

$6(9 \%)$

1.0

$84(72-102) \quad 0.03$

$2(3 \%)$

1.0

$4(3-8)$

0.18

$4(6 \%)$

0.20

$46(43-96) \quad 0.19$

$12(18 \%) \quad 0.81$

$3(3 \%)$

0.70

$1(2 \%)$

0.43

0

$22(33 \%)$

Results are given as $\mathrm{n}(\%)$ or as median $\left(1^{\text {st }}-3^{\text {rd }}\right.$ quartile). ASAT $=$ Aspartate aminotransferase; CK-MB = Creatine kinase-muscle, brain isotype; ICU = Intensive care unit. 
Table 4. Univariate analysis of potential risk factors for PHF.

Variable n (\%) of PHF n (\%) Odds Ratio CI(95\%) $p$ Value patients

$116 \quad 47(41 \%)$

Sex

Male

Female

$77(66 \%) \quad 35(45 \%)$

1.00

39 (34\%) 12 (31\%)

0.53

$0.2-1.2$

0.13

Age (years)

$<70$

$70-79$

$\geq 80$

Mean: 70

Congestive heart failure

No

Yes

$$
47 \text { (38\%) } 10(21 \%)
$$

69 (59\%) $\quad 37$ (54\%)

4.28

$0.4-1.8$

0.65

$14(12 \%) \quad 3(21 \%)$

0.33

$0.1-1.3$

0.11

0.96

0.9-1.01

0.11

Peripheral artery disease

No

$108(94 \%) \quad 43(40 \%) \quad 1.00$

Yes

$$
7 \text { (6\%) } \quad 4(57 \%)
$$

$0.4-9.6$

0.04

Creatinine clearance $<50 \mathrm{~mL} /$ minute

No

Yes

Mean: 70

$86(74 \%) \quad 31(36 \%) \quad 1.00$

$30(26 \%) \quad 16(53 \%)$

2.03

$0.9-4.7$

0.01

$0.99 \quad 0.98-1.01 \quad 0.28$

New York Heart Association class

I/II

$33(28 \%) \quad 10(30 \%) \quad 1.00$ 
Boano et al.

III/IV

$83(72 \%) \quad 37(45 \%)$

1.85

0.8- 4.4

0.16

$\mathrm{RV}$ diameter index (RV/BSA $\left.\left(\mathrm{mm} / \mathrm{m}^{2}\right)\right)$

Mean: 21

$1.09 \quad 0.96-1.2 \quad 0.17$

LV ejection fraction $\geq 40 \%$
Yes
$100(88 \%) \quad 38(38 \%)$
1.00
No
$14(12 \%) \quad 8(57 \%)$
$2.17 \quad 0.7-6.8$
0.2

TAPSE $<20 \mathrm{~mm}$
No
$70(65 \%) \quad 32(46 \%) \quad 1.00$
Yes
38 (35\%) $11(29 \%)$
2.07
0.9-4.9 $\quad 0.09$
Mean: 18
$0.91 \quad 0.8-1.02$
0.1

Cryoablation

$\begin{array}{llllll}\text { No } & 66(57 \%) & 22(33 \%) & 1.00 & & \\ \text { Yes } & 50(43 \%) & 25(50 \%) & 2.00 & 0.9-4.3 & 0.07\end{array}$

Cross-clamp time (minutes)

$<120$

$70(60 \%) \quad 19(27 \%) \quad 1.00$

120-150

37 (32\%) $\quad 21(57 \%)$

3.50

1.5-8.2 0.003

$>150$

$9(8 \%) \quad 7(78 \%)$

9.40

1.7- $50 \quad 0.008$

Mean: 112

$1.02 \quad 1.01-1.04 \quad 0.001$

$\mathrm{AF}=$ atrial fibrillation; $\mathrm{BSA}=$ body surface area; $\mathrm{CI}=$ confidence interval; $\mathrm{LV}=$ left ventricle; $\mathrm{PHF}=$ postoperative heart failure; $\mathrm{RV}=$ right ventricle; $\mathrm{TAPSE}=$ tricuspid annular plane systolic excursion. 


\section{Table legends}

Table 1. AVR = aortic valve surgery; $\mathrm{CABG}=$ coronary artery bypass grafting; $\mathrm{MVS}=$ mitral valve surgery; TVS = tricuspid valve surgery.

Table 2. Results are given as n (\%) or as median (1st - 3rd quartile). BSA = body surface area; $\mathrm{LA}=$ left atrium; $\mathrm{LV}=$ left ventricle; $\mathrm{RA}=$ right atrium; $\mathrm{RV}=$ right ventricle.

Table 3. Results are given as $\mathrm{n}(\%)$ or as median $\left(1^{\text {st }}-3^{\text {rd }}\right.$ quartile $)$. ASAT $=$ Aspartate aminotransferase; CK-MB = Creatine kinase-muscle, brain isotype; ICU = Intensive care unit.

Table 4. AF = atrial fibrillation; $\mathrm{BSA}=$ body surface area; $\mathrm{CI}=$ confidence interval; $\mathrm{LV}=$ left ventricle; $\mathrm{PHF}=$ postoperative heart failure; RV = right ventricle; TAPSE = tricuspid annular plane systolic excursion.

\section{Figure legend}

Figure 1. Kaplan-Meier cumulative proportion survival curves for patients with and without concomitant Cox-maze IV cryoablation procedure. 


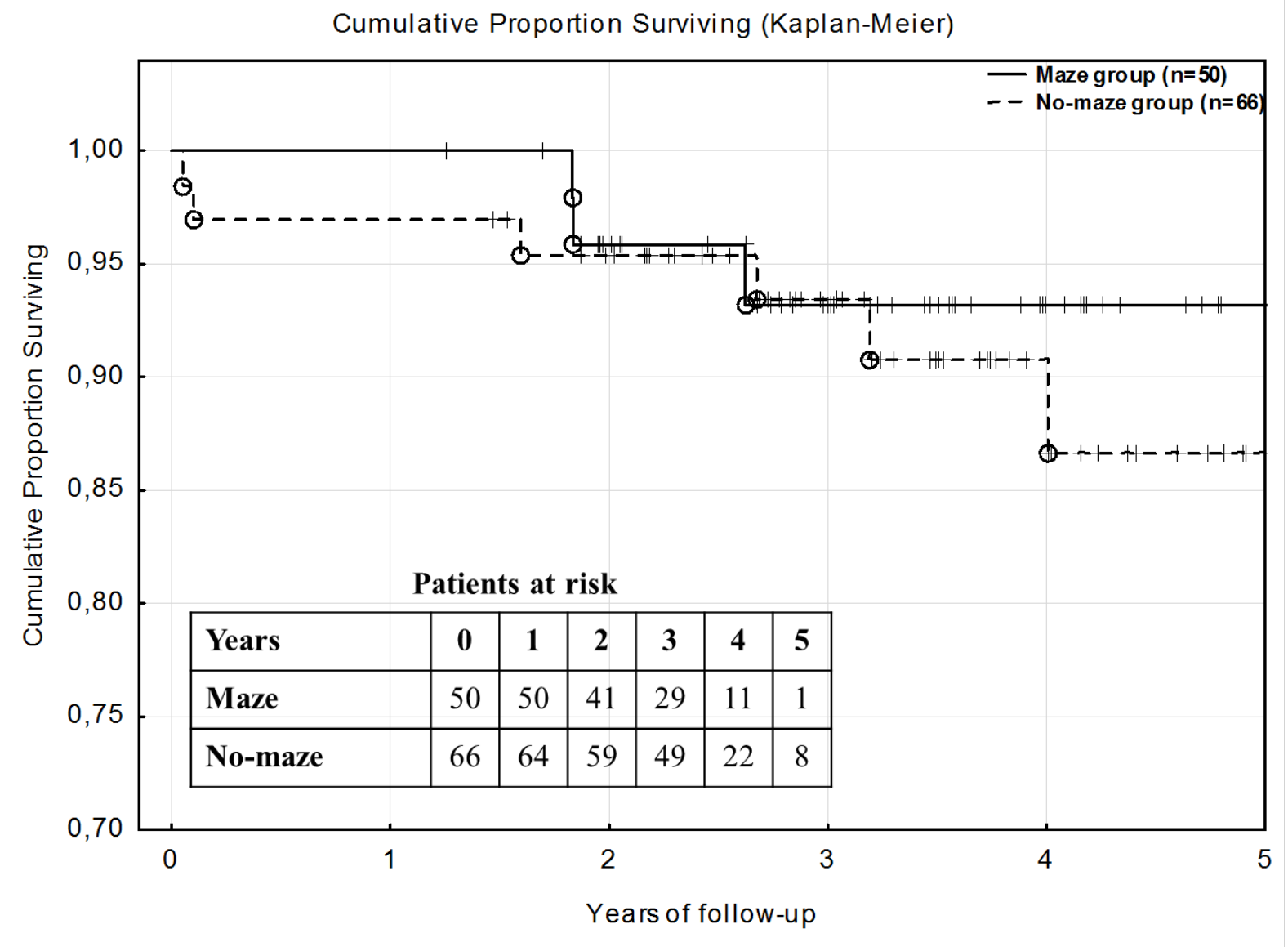

Figure 1. Kaplan-Meier cumulative proportion survival curves for patients with and without concomitant Cox-maze IV cryoablation procedure. 